\title{
Examining the Utility of Photovoice as an Audiological Counseling Tool
}

DOI: $10.3766 /$ jaaa.18034

\author{
Gabrielle H. Saunders*† \\ Lauren K. Dillard*ł \\ Melissa T. Frederick* \\ ShienPei C. Silverman*
}

\begin{abstract}
Background: Photovoice is a participatory action research method in which people take photographs to represent real-world experiences, so that issues of interest/concern can be documented. There are no published studies in which photovoice has been used in audiological rehabilitation (AR). The purpose of this feasibility study was to examine whether photovoice could have application in audiology.
\end{abstract}

Purpose: A feasibility study was designed to determine whether photovoice could be adapted for use as a clinical auditory rehabilitation tool (1) to facilitate provision of tailored communication strategy counseling, (2) as a post-hearing aid fitting counseling tool, (3) to enhance communication between partners regarding hearing loss, and (4) to provide an understanding of the emotional impacts of hearing loss.

Research Design: In this combined qualitative and quantitative feasibility study, a photovoice intervention was given to four groups of participants.

Study Sample: Twenty-four individuals were recruited from a research subject data repository at the National Center for Rehabilitative Auditory Research.

Data Collection and Analysis: The study involved two visits to the laboratory during which participants received instruction in photovoice methodology (visit 1) and then, one to two weeks later, discussed their photographs during a debriefing session (visit 2).

Results: The mean number of photographs taken by participants was 12.6 (range: 4-29); the mean duration of the debriefing sessions was 40:39 min:sec (range: 14:30-66:22 min:sec). Participants reported that participating had made them think more about their hearing problems, appreciate their hearing aids more, and be more aware of the situations in which their hearing aids did and did not help. The taking and discussion of the photographs was also described as a learning tool, and it had facilitated conversations with others about hearing problems. Participants who completed the study with their communication partner (use case 3) said it had assisted with problem-solving and gave insight into the perspective of their partner. The research team noted that photovoice facilitated highly tailored counseling and provision of evidence-based recommendations for hearing assistive technology, enhanced interaction between communication partners, provided insight into participants' lifestyle and communication needs, and seemed to generate rapport and trust.

Conclusions: This feasibility study indicated that participants were willing to engage in photovoice and that it could be used to guide selection of rehabilitation recommendations and for postfitting counseling. Its application in audiological practice would seem timely and valuable for improving patient-centered and family-centered AR.

*VA RR\&D National Center for Rehabilitative Auditory Research, Portland VA Medical Center, Portland, OR; †Eriksholm Research Centre, Snekkersten, Denmark; $\ddagger$ Communication Sciences and Disorders, University of Wisconsin, Madison, WI

Corresponding author: Gabrielle H. Saunders, VA RR\&D National Center for Rehabilitative Auditory Research, Portland VA Medical Center, Portland, OR, and Eriksholm Research Centre, Snekkersten, Denmark; Email: gasa@eriksholm.com

This study was supported by funding by the Department of Veterans Affairs (VA), Veterans Health Administration, VA Office of Research and Development award \#C9230C.

Aspects of this work were presented at the American Auditory Society Meeting, Scottsdale, AZ, March 1-3, 2018.

The views are those of the authors and do not necessarily represent the position or policy of the US Department of Veterans Affairs or the US government. 
Key Words: auditory rehabilitation, counseling, hearing aids and assistive listening devices, photo voice

Abbreviations: app = application; $\mathrm{AR}=$ audiological rehabilitation

$\mathrm{P}$ hotovoice is a participatory action research method in which people take photographs to represent real-world experiences that are under study, so that issues of interest/concern can be documented and discussed. Individuals or a group of individuals are tasked with photographing objects, places, and situations that represent the question of interest. The photographs are briefly annotated by the individual and later discussed with the facilitator to explain why the photograph was taken and what it represents. Data are then compiled and used to provide insight into the individual's or the group's real-world experiences.

Photovoice has been applied to health research in a variety of ways. It has been used to document the experiences of people living with chronic pain (Baker and Wang, 2006), prostate cancer (Oliffe and Bottorff, 2007), and mental illness (Clements, 2012), for exploring health-care access and use (Rosen et al, 2011; Kowitt et al, 2015; True et al, 2015), and for documenting health-care needs (Angelo and Egan, 2015; Gill et al, 2016). The purposes of these studies were to promote community awareness of issues, implement programs to address needs, and/or change public policy.

Other researchers have adapted photovoice methodology and used photographic images in clinical care. For example, Baker and Wang (2006) examined the potential use of photovoice to assess the pain experience by having participants photograph objects that reflected their experiences with chronic pain and objects that reflected what they would like their lives to be like without chronic pain. Participants attended a one-on-one exit interview during which they were asked about their participation in the study, their experience as a photographer, and their overall experience with pain. The authors reported that the technique helped participants share their experiences of living with chronic pain and suggested it could assist individuals who work with populations who experience chronic pain to better understand and assess the way chronic pain impacts the patient's life. In another study, Linz et al (2016) used patient videos (instead of photographs) as a form of support during recovery from mental illness. They found that individuals in their video intervention group were better able to think about day-to-day changes in the emotional state, feelings of isolation, and their hopes for the future. Furthermore, the participants reported that the videos could help others by educating potential viewers about the impacts of mental illness. Ginicola et al (2012) described why photovoice, or as they referred to it-phototherapy, can be beneficial for counseling. They used specific case examples to illustrate how photographs helped build rapport with a client by allowing the counselor to learn about the individual on a personal level such as their hobbies, likes, and dislikes, and noted that by looking for themes within the photographs, it could be used to assist with choosing types of intervention strategies. Guerra et al (2013) used photovoice as an outcome measure to identify the positive and negative impacts of a program that supports families caring for a relative with dementia. The participants were instructed to take photographs over a three-month period and to then select photographs that represented positive and negative impacts of the program. Participants reported that although they initially had concerns about translating ideas into photographs, it was actually easier than expected. They said the process helped them reflect on their caregiving situation and the implications that it had for their family. They also reported that photovoice facilitated communication about their situation with others, reported that it allowed them to explore and interpret their own feelings, and reported it to be more proactive in how they chose to represent themselves and others. Finally, Sackett and Jenkins (2015) provided a hypothetical case example in which they proposed photovoice could be used as a tool for individual counseling sessions. Although hypothetical, the case illustrated how personal photographs could potentially facilitate emotionally charged discussions.

To our knowledge, there are no published studies in which photovoice has been used as a tool in audiological rehabilitation (AR), although Saunders et al (2017) used preselected, emotionally evocative photographs as a tool to encourage reflection about the impacts of hearing difficulties. The IDA Institute (https://idainstitute.com), an organization that works with hearing care professionals from around the world to develop and integrate person-centered care in hearing rehabilitation, has developed AR tools that use photographs. Specifically, the photographs are used as talking points to develop strategies for improving communication (Living Well tool), to help individuals prepare for an initial clinical visit at which hearing difficulties and management strategies are discussed, and to prompt reflection on how improving hearing and communication would affect their daily life (Ida Telecare tools). Whereas the former tool uses only preselected photographs, the latter allows individuals to provide their own photographs as well. Saunders et al (2017) showed promising outcomes; however, there are no published data on the effectiveness of the IDA tools.

There are many reasons why an adaptation of photovoice could have potential value in audiology practice. 
Photographs could provide the audiologist with insight about an individual's lifestyle, communication priorities, and the specific environments in which they communicate. Photographs could also be used to assist with making rehabilitation recommendations, or when providing highly tailored communication strategies for specific listening situations. Photographs also have the potential to facilitate self-reflection and increase the patient's awareness of his/her successes and difficulties with hearing aids and/or specific listening situations. Finally, photographs could play a role in providing perspective for communication partners about the impacts hearing loss has on the dyad. With the recent recommendations to include a family member in adult AR (Grenness et al, 2016; Singh et al, 2016), this could have considerable value.

Another potentially valuable aspect of photovoice is that, by its very nature, it facilitates patient-centered communication (Lorenz and Chilingerian, 2011). Although audiologists and patients report a preference for patient-centered care (Laplante-Lévesque et al, 2014; Poost-Foroosh et al, 2015), the style of communication used by audiologists is often not consistent with such an approach (Ekberg et al, 2014a; Grenness et al, 2015; Pryce et al, 2016; Sciacca et al, 2017). As such, discussion of a patient's photographs could facilitate patient-centered communication during clinical encounters by opening up personal conversations about hearing and communication.

Because photovoice has not been used before as a clinical tool in AR, is it is appropriate to conduct a feasibility study to assess whether it is a novel intervention and is worthy of further testing in a full-scale trial. This is because feasibility studies are relatively cost and time efficient and the methodology can be flexible and iterative (i.e., the methods can be adapted as new information is learned); furthermore, it is acceptable to use a convenience sample with limited statistical power for the testing (Bowen et al, 2009; Orsmond and Cohn, 2015). Typically, and as is the case here, feasibility studies are used to examine factors such as recruitment capacity, that is, "Are people willing to take part?"; procedures and measures, that is, "How should the intervention be used and what outcomes should be measured?"; intervention acceptability, that is, "Do recipients find the intervention acceptable?"; resources required for implementation, that is, "How much time, etc., is needed for implementation?"; and preliminary outcomes, that is, "Does the intervention appear to indicate positive outcomes?" (Orsmond and Cohn, 2015).

The purpose of this study, therefore, was to examine the feasibility of adapting photovoice by using patient photographs as an audiological counseling tool. Given the widespread presence of cellphone cameras, photovoice would appear to be a feasible and timely way to improve the provision of AR. To this end, a feasibility study was designed to determine whether photovoice could be applied to four aspects of AR: (a) to facilitate provision of tailored communication strategy counseling, (b) as a post-hearing aid fitting counseling tool, (c) to enhance communication between partners regarding hearing loss, and (d) to provide an understanding of the emotional impacts of hearing loss.

\section{METHODS}

\section{Study Synopsis}

The feasibility of using photovoice for four aspects of AR was examined in which participants attended two study visits. During visit 1 , participants were instructed in the photovoice methodology and were given a specific photographic task, dependent on the AR application. During visit 2, the photographs taken by each participant were discussed during a debriefing session.

This work was approved by the Institutional Review Board and the Research and Development Committee at the VA Portland Health Care System.

\section{Study Design}

The study examined the feasibility of applying photovoice to four aspects of $\mathrm{AR}$ as follows:

- To determine whether it is feasible to use photovoice as a tool to facilitate provision of tailored communication strategy counseling, five individuals with hearing loss were instructed to take photographs of situations in which they had encountered hearing difficulties.

- To determine whether it is feasible to use photovoice as a post-hearing aid fitting counseling tool, four individuals who had been fitted with their first pair of hearing aids within the prior three months were asked to take photographs of typical daily activities in which they found their hearing aids either particularly helpful or particularly problematic.

- To determine whether it is feasible to use photovoice to enhance communication between partners regarding hearing loss, five individuals with hearing loss and a partner were asked to take photographs that represented the typical shared daily activities in which communication was a problem. Partners were asked to take photographs independently so that the perspective of both individuals would be represented.

- To determine whether it is feasible to use photovoice to provide insight into the emotional impacts of hearing loss, five individuals with hearing loss were instructed to take photographs that showed what having a hearing loss meant to them. 


\section{Participants}

Participants were individuals recruited from a data repository at the National Center for Rehabilitative Auditory Research. The data repository holds contact information and audiometric data of prior study participants who agreed to be contacted for future studies. Audiometric thresholds stored in the database were used to find individuals with $1 \mathrm{kHz}$ thresholds $\geq 40 \mathrm{~dB}$ HL in both ears. In addition, participants were required to own a smart phone with a camera and be comfortable using it to take photographs. Demographic and audiometric data, including age, gender, and puretone thresholds, were not extracted from the database nor were they collected for this feasibility study. To determine the feasibility of using photovoice to enhance communication between partners, potential participants were required to have a partner who was also willing to take part. Table 1 provides all available information about the participants.

\section{Payment}

Participants received $\$ 25$ for attending study visit 1 and $\$ 75$ for attending study visit 2 .

\section{Procedures}

\section{Study Visit 1: Instruction}

Participants underwent a written informed consent process to confirm that they understood the study purpose and procedures. They were then instructed in the photovoice procedure which was supplemented with a takehome booklet (see Supplemental Material S1, available with the online version of this article). The booklet described the photovoice methodology, provided studyspecific goals and instructions, and stressed the need to maintain the privacy of individuals who might be photographed. To assist with this, the booklet specified strategies for taking photographs in which a person could not be identified, such as taking photographs from the neck down, from behind the person, and from far away. The training curriculum and supplemental booklet were developed based on the training used by Ono (personal communication) for an ongoing VA Health Services Research and Development study.

Key components of the instructions were as follows:

- Take 20-25 photographs over a one-week period with a smartphone. Note: After testing about 15 participants, the number of photographs individuals were instructed to take was decreased to $10-15$, for two reasons: (a) many participants reported it was stressful to find content for 20-25 different photographs and (b) the investigators observed that after discussing 10-15 photographs; no further information was being learned and no new advice was being given.

- Write a sentence or two about each photograph describing what it represents and why it was taken.

- Email the photographs to the study team at the end of the week.

- Avoid taking photographs of people's faces or have the individual sign a photo release form.

- Avoid taking photographs on the VA Portland Health Care System campus because it is not permitted by federal regulations.

To confirm whether participants understood the study instructions, they were asked to give one or two examples of photographs they might take and how they might annotate them. At the end of the instruction process, participants were given a copy of the instruction booklet and 20 photo release forms to take home.

\section{Reminder Phone Call}

One to two weeks later, participants received a reminder call to email their photographs to the study team. If a participant sent any images that included an individual who could be identified, the photograph was immediately edited by placing a colored circle over

Table 1. Participant Information

\begin{tabular}{|c|c|c|c|}
\hline Aspect of AR Investigated & Participants (n) & $\begin{array}{l}\text { Participants with } \\
\text { Hearing Aids ( } \mathrm{n})\end{array}$ & Eligibility Criteria \\
\hline $\begin{array}{l}\text { Use of photovoice to facilitate tailored } \\
\text { communication strategy counseling }\end{array}$ & 5 & 3 & Hearing impairment* \\
\hline $\begin{array}{l}\text { Use of photovoice as a post-hearing aid } \\
\text { fitting counseling tool }\end{array}$ & 4 & 4 & $\begin{array}{l}\text { Received first pair of hearing } \\
\text { aids within prior } 6 \text { months }\end{array}$ \\
\hline $\begin{array}{l}\text { Use of photovoice to enhance } \\
\text { communication between partners }\end{array}$ & 5 communication dyads & 5 & $\begin{array}{l}\text { Hearing impairment and a } \\
\text { communication partner } \dagger \text { willing } \\
\text { to participate }\end{array}$ \\
\hline $\begin{array}{l}\text { Use of photovoice to understand the } \\
\text { emotional impacts of hearing loss }\end{array}$ & 5 & 4 & Hearing impairment \\
\hline
\end{tabular}

*Hearing impairment defined as $1-\mathrm{kHz}$ thresholds $\geq 40-\mathrm{dB} \mathrm{HL}$ in both ears.

† Hearing status of the communication partner was not assessed nor collected via self-report. 
the identifiable face. Of the 189 photographs received, just 12 included identifiable content.

\section{Study Visit 2: Debriefing}

Two or three members of the research team attended each debriefing session. The research team consisted of a clinical audiologist (M.T.F.), an Au.D. student completing her $4^{\text {th }}$ year clinical placement (L.K.D.), a sociologist (S.C.S.), and an AR researcher (G.H.S.). M.T.F. and/or L.K.D. were present during all debriefing sessions, and G.H.S. was present for all but three debriefing sessions. All present were given a printed copy of the participant's photographs on which to take written notes. Although previously agreed to via informed consent, the research team confirmed participants were comfortable with the discussion being audio recorded. A discussion of each photograph was then led by a member of the research team. In general, participants were asked to describe what each photograph represented and why they had taken it. However, depending on the AR application being examined, there were some differences in the follow-up questions and advice provided, as follows.

When examining the feasibility of using photovoice for counseling regarding communication strategies, followup questions included asking participants what they had done when they encountered a specific communication problem and whether it had helped. The research team suggested situation-specific communication strategies as appropriate.

When examining the feasibility of using photovoice for post-hearing aid fitting counseling, follow-up questions included asking participants how they typically coped in the problematic situations they had identified, and to think about ways in which the problematic listening situations differed from the ones in which their hearing aids helped them. This was performed so they could identify for themselves how they might manage better. Advice regarding hearing aid accessories and communication strategies for the photograph-specific listening situations was also provided.

When examining the feasibility of using photovoice for enhancing communication between partners about hearing-related matters, communication partners were asked to comment on one another's photographs and commentary. They were asked how they viewed each other's perspective on a situation and were prompted to request suggestions from one another that might help in problematic listening conditions. The research team also provided recommendations for solving communication problems.

When examining the feasibility of using photovoice to provide an understanding of how it feels to live with hearing loss, the research team asked follow-up questions only; they did not provide advice or input. Follow- up questions included "how did that make you feel" and "what emotion or adjective would you use to describe your feelings at the time."

Once each photograph had been discussed, the research team asked all participants the following questions:

- Did you capture in a photograph everything you wanted to represent, and if not, what else would you like to have photographed?

- Was the week during which you took the photographs a typical week and if not, how did it differ?

- What did you think about taking the photographs?

- Did you learn anything from taking part in the study?

After completing several debriefing sessions, an additional question was asked of individuals to determine whether participants would consider the method clinically acceptable:

- What would you think if your audiologist asked you to take photographs before attending your next clinic visit?

Note: Individuals tasked with taking photographs that depicted how it feels to live with hearing loss were not asked this final question because the photographic task did not have immediate clinical application; thus, just 12 of the 24 participants responded to this question.

\section{Data Analysis}

Descriptive statistics were used to document the number of photographs taken and the duration of the debriefing sessions; qualitative description (Sandelowski, 2000) was used to describe the qualitative findings.

\section{RESULTS}

\section{Quantitative Data}

Table 2 provides information about the number of photographs and duration of the debriefing sessions. Based on the many photographs received and the duration of the debriefing sessions, it seems that the photovoice procedure was acceptable to participants. All 20 participants who were asked whether the prior week had been a typical week, agreed it has been, and all but four reported they had captured everything they wanted to represent in a photograph. Of those who did not capture everything, two said that taking a photograph in the missing situation would have been inappropriate (in a church, on the bus, and at a store checkout), one said it would have been dangerous (while driving the car), and one said the situation was not encountered that week (going to a restaurant). 


\begin{tabular}{|c|c|c|}
\hline Aspect of AR Investigated & $\begin{array}{c}\text { No. of Photographs } \\
\text { Mean (SD) } \\
\text { Range }\end{array}$ & $\begin{array}{c}\text { Duration of Debriefing } \\
\text { Session (min:sec) } \\
\text { Mean (SD) } \\
\text { Range }\end{array}$ \\
\hline Use of photovoice to facilitate tailored communication strategy & $16.6(9.2)$ & $43: 55(16: 19)$ \\
\hline counseling & $4-29$ & $23: 25-64: 26$ \\
\hline Use of photovoice as a post-hearing aid fitting counseling tool & $\begin{array}{c}15.0(8.1) \\
5-23\end{array}$ & $\begin{array}{l}39: 07(7: 50) \\
31: 35-50: 04\end{array}$ \\
\hline Use of photovoice to enhance communication between partners & $\begin{array}{c}11.3(3.7) \\
7-17\end{array}$ & $\begin{array}{l}54: 40(9: 44) \\
43: 48-66: 22\end{array}$ \\
\hline $\begin{array}{l}\text { Use of photovoice to understand the emotional impacts of } \\
\text { hearing loss }\end{array}$ & $\begin{array}{c}9.2^{*}(3.1) \\
6-14\end{array}$ & $\begin{array}{l}24: 37(11.32) \\
14: 30-39: 00\end{array}$ \\
\hline
\end{tabular}

${ }^{*}$ After testing about 15 participants, the number of photographs requested was decreased to 10-15. SD = Standard deviation.

\section{Qualitative Data: Patient Perspectives}

Opinions about the study were generally positive. Some participants stated that taking the photographs was enjoyable, interesting, informative, and fun. Others, however, said it had been challenging to avoid taking photographs of people's faces, burdensome to re- member to take photographs, and a little harder than expected to find a variety of subject matter. When asked what they thought about the study and what, if anything, they had learned, participants said that participation had made them think more about their hearing problems, appreciate their hearing aids more, and became aware of the situations in which their hearing aids

\section{Table 3. Illustrative Quotes from Participants}

\begin{tabular}{|c|c|}
\hline Qualitative Description & Quote \\
\hline Sharing with others & $\begin{array}{l}\text { I enjoyed doing this and because I eventually told people what I was doing, I brought it up in } \\
\text { conversation and then it helped create understanding and create also people's willingness to } \\
\text { bring something up that they might not have brought up... }\end{array}$ \\
\hline \multirow[t]{5}{*}{ Learning and problem-solving } & $\begin{array}{l}\text { It made me think about what areas do I have problems hearing and what things could be done to } \\
\text { help them out. }\end{array}$ \\
\hline & $\begin{array}{l}\text { It's made me think concretely about specific things- specific losses- but that hasn't depressed } \\
\text { me... it's made me adapt. I think it made me more aware and pay more attention. You know, } \\
\text { speak up, tell people. }\end{array}$ \\
\hline & ... and it was interesting to me to reflect- where exactly do I have challenges and where don't I? \\
\hline & $\begin{array}{l}\text { It made you think a bit more... What the real challenges are, instead of just living those challenges, } \\
\text { thinking of the challenges. }\end{array}$ \\
\hline & $\begin{array}{l}\text { When someone is first exploring their hearing loss, this activity is to get a picture of where the } \\
\text { problem areas are... [it] may be very helpful in figuring out what are those options for hearing, } \\
\text { whether it's devices or settings. }\end{array}$ \\
\hline Facilitating conversation & $\begin{array}{l}\text { It did force us to think about more of the situations... it was positive because it gives us an } \\
\text { opportunity to be more aware of what's going on and get some of our frustrations out in the open. }\end{array}$ \\
\hline \multirow[t]{3}{*}{ Hearing aid use } & I wore the hearing aids, which is something I was avoiding before. \\
\hline & $\begin{array}{l}\text { But then I decided, look, you got the hearing aids to help you hear so now I try to wear them every } \\
\text { day. }\end{array}$ \\
\hline & $\begin{array}{l}\text {...so it made me realize that I had to wear them all the time, instead of like wear them three days and } \\
\text { then don't wear them two days, and then wear them one day and then don't wear them two days. } \\
\text { You know, that's what I was doing. }\end{array}$ \\
\hline \multirow[t]{4}{*}{ Appreciation of hearing aids } & $\begin{array}{l}\text { It made me appreciate wearing my hearing aids more. There was a period where I was like- oh, I } \\
\text { don't need them... }\end{array}$ \\
\hline & $\begin{array}{l}\text { I never really thought about my hearing aids in the way that they worked for me or didn't work for me, } \\
\text { I just did 'em and went "maybe I don't like these and maybe I'm not going to be able to wear } \\
\text { them" and I've had them adjusted like } 2 \text { or maybe } 3 \text { times. }\end{array}$ \\
\hline & $\begin{array}{l}\text { What I found was that the sounds that were pleasant to me and that I enjoyed were mostly outside } \\
\text { and that surprised me. }\end{array}$ \\
\hline & It made me appreciate them because it made me feel safer... \\
\hline \multirow[t]{2}{*}{ Empathy for others } & ... it gives me a little bit more insight into people that are fully deaf \\
\hline & $\begin{array}{l}\text { I think the idea of having the couples come in and share like this is really good because it does give } \\
\text { the hearing partner a better appreciation as to why [my partner] isn't paying attention to me. }\end{array}$ \\
\hline
\end{tabular}


were and were not helpful. Some also said the exercise had been a learning tool, and one noted it had facilitated conversations with others about hearing problems. Specifically, the individual shared that during a barbeque at a friend's house, she had explained to the other guests why she was taking photographs which led to a conversation about her hearing difficulties and the hearing difficulties that others in the group were also experiencing at the gathering. The group then discussed how they could best communicate with one another. The participant said she had never discussed her hearing loss with this group of friends before and that doing so was helpful to her, as well as to them. The communication dyads said that the exercise had made them think about problems and find ways to solve them together, that it allowed them to get problems out into the open, and that it gave them insight into the perspective of their partner. Table 3 provides quotes from participants that illustrate these points.

Table 4 shows the emotions assigned to photographs by participants in use case 4 (understanding how it feels to live with hearing loss). In addition to those in the table, the emotions of handicapped, humility, empathy, hesitance, neutrality, and skepticism were assigned by just one participant to a single photograph. It is noteworthy that participants identified both positive and negative emotions during this task.

\section{Qualitative Data: Research Team Perspectives}

The research team noted several outcomes that could positively benefit AR, as follows.

\section{Highly Tailored Counseling}

Using photographs as the basis for conversation facilitated the provision of highly tailored counseling, and it seemed that having a concrete situation to discuss enabled participants to better identify with the information than had it been provided without the aid of the photographs. For example, one participant shared a photograph of his partner (wife) sitting directly in front of a window at the kitchen table. The participant described that he often had trouble hearing her during meals. The research team suggested changing the seating arrangement so the wife's face was not backlit would likely make it easier for him to gain information from his wife's face and lips. Because the photograph was taken in the kitchen, the research team also asked whether there was a nearby stove with a fan and suggested ensuring the stove fan is off during mealtimes. Although this advice is fairly standard, being able to provide it in the context of a photograph of participant's home is likely to result in better recall and application, as illustrated by numerous studies showing that the use of pictures or pictographs increases recall and understanding of health education information, particularly among those with low literacy (see Houts et al, 2006, for review).

\section{Enhanced Interaction between Communication Partners}

The photovoice process seemed to facilitate interactions between communication partners that may have been more difficult to initiate without the photographs, and these interactions appeared to lead to mutual understanding between partners. For example, a communication partner shared a photograph of a restaurant. She described that it represented her being the gobetween for her hearing-impaired husband and the wait staff. She said that although she understood it was a problem for her husband to hear and wanted to help him, she was uncomfortable being the go-between and never knew when she should intervene. When asked for his perspective, the hearing-impaired husband said he relied on his wife because he did not want to impose on wait staff to repeat things. Both partners said they were uncomfortable with the present approach, and noted they had not known their partner was also uncomfortable with it. The research team raised the notion with the hearing-impaired partner that polite self-advocacy was completely acceptable, and suggested that asking wait staff to speak more slowly, move closer, and look directly at him was completely appropriate. Both partners responded positively to this advice. In another case, a hearing-impaired

Table 4. Emotions Assigned to Photographs by Participants Describing the Emotional Impacts of Living with Hearing Loss

\begin{tabular}{lcc}
\hline Emotion & $\begin{array}{c}\text { No. of Participants who Assigned } \\
\text { Emotion to } \geq 1 \text { Photograph (max =5) }\end{array}$ & $\begin{array}{c}\text { No. of Photographs to Which } \\
\text { Word Was Assigned }\end{array}$ \\
\hline Frustration, annoyance, irritation, and stress & 4 & 23 \\
Sad and depressed & 4 & 12 \\
Left out, isolation, missing out, and hard to be there & 3 & 9 \\
Peace, relaxation, joy, comfort, and relief & 2 & 13 \\
Anger & 2 & 2 \\
Fear & 1 & 3 \\
Gratefulness & 1 & 3 \\
Embarrassment & 1 & 2 \\
\hline
\end{tabular}


partner showed a photograph of his tablet computer. He said it represented him not hearing his wife when he was using the tablet. He noted that she would begin talking without first getting his attention, and that he, therefore, missed much of the content. His wife responded that this was the case, and added that she found it frustrating because he was almost always using some form of technology (tablet, cellphone) and/or also watching the television, so there was never a suitable time to converse. This led to a discussion about making dedicated time for conversation during which all distractions were removed. The wife noted that an appropriate time for this would be just before going to sleep while in bed but mentioned that currently it was not possible because her partner removed his hearing aids before getting into bed. Without being prompted, the couple then discussed the possibility that the husband wears his hearing aids in bed for a few minutes each night so that they could have a conversation.

\section{Evidence-Based Recommendations for Hearing Assistive Technology}

The photographs enabled the research team to give recommendations for hearing technology that was highly specific to individual needs. For example, a participant who was a cab driver shared a photograph taken from the back seat of his taxi cab that he said represented his inability to hear passengers seated in the back seat of the cab. He said he was distressed at not hearing the passengers because he was concerned that they thought him rude when he did not reply. The research team suggested he consider purchasing a remote microphone for his hearing aids that could be attached to the back of his seat. The photograph was used to illustrate possible placement of the remote microphone.

\section{Insight into Participants' Lifestyle and Communication Needs}

A brief examination of a participant's photographs provided considerable insight into his/her lifestyle, and as a group, the range of activities they engaged in. It was clear that some participants were highly social, sharing photographs of gatherings with friends and in restaurants, others engaged primarily in outdoor activities, sharing photographs of a walk in the countryside or out jogging, whereas others primarily shared photographs taken within their home.

\section{Rapport and Trust}

As seen from Table 2, participants were willing to spend time discussing their photographs. The content of the discussion was often very personal and involved the sharing of feelings both about hearing loss/communication, and sometimes other unrelated matters. Although the latter is not applicable to AR, we interpret this to indicate that the participants trusted the research team and that a positive rapport was generated, and based on the extremely personal nature of the content shared, we suggest that the photographs might have helped with this.

\section{Hearing Aid Appreciation}

When examining the feasibility of using photovoice as a post-hearing aid fitting counseling tool, participants were instructed to document both positive and negative hearing aid experiences. Being asked to reflect on the positive and the negative experiences seemed to result in increased appreciation of the hearing aids. Although this cannot be attributed to photovoice per se, it is nonetheless an important observation. For instance, one individual shared a photograph of leaves on the ground. She noted that because she was thinking about the positive impacts of her hearing aids, she became aware of how much she enjoys the sound of walking through crackling leaves and other outdoor sounds-something she could not appreciate without her hearing aids. She said that although she originally obtained the hearing aids to assist with indoor conversation, the instruction had made her realize how enjoyable it was for her to hear outside and that as a result, she was now using her hearing aids more consistently. Another individual noted that having spent time trying to understand where his hearing aids were and were not helpful, he came to the realization that he should wear them all the time, rather than sporadically as he had been before participating in the study.

\section{DISCUSSION}

$\mathrm{T}$ his study assessed the feasibility of adapting photovoice methodology for use in audiological practice. The data showed that participants were willing to take and discuss photographs, that the photographs they provided depicted various aspects of hearing and communication, and that, for the most part, reflected the content we expected based on the instructions provided. In fact, participants were so willing to discuss their photographs that the duration of the debriefing visits was long-too long to be clinically practical. However, for the study, the research team encouraged in-depth debriefing, and did not attempt to limit the discussion. In a clinical setting, the debriefing session could be considerably shortened by requesting fewer photographs and encouraging patients to focus their discussion on directly relevant content. Based on the comments from some participants, who said it was challenging to take photographs in multiple unique situations, limiting the number of photographs might be advantageous. 
If photovoice is to be used as a clinical tool, patients must understand its value because adherence to clinical recommendations is impacted by whether the patient agrees with those recommendations (Davis et al, 2002). It is, therefore, reassuring that just three of the 24 participants were skeptical of the process; the remainder could see its potential value as a clinical tool. Of course, we do not know whether patients attending a clinical appointment would be willing to participate in a photovoice activity. Of the nine participants who were asked what they would think about bringing photographs to a clinical appointment if their audiologist requested it of them, six said they would be willing to do so if the audiologist thought it would be helpful, two did not have an opinion on the matter, and one said he/she would be suspicious of the audiologist's motives. Thus, although clinical use of photovoice might not be acceptable to all patients, it would likely be acceptable to many. In instances in which the patient was unwilling to share personal photographs, one could provide the patient with preselected photographs to discuss in the manner used by the IDA Institute. This would limit the extent to which the conversation could be highly tailored but nonetheless, it could prove valuable.

Another consideration if photovoice is to be used as a clinical tool is maintaining the privacy of the individuals in photographs that are shared with a clinician. It is critical to ensure that the photographer is aware of the need for this. In this study, it seems that most participants understood the importance of privacy, in that just 12 of the 189 photographs received had identifiable content. It suggests that the instructions and supplemental take-home booklet provided were effective in transmitting the intended message. However, it would presumably be possible to develop an app that automatically detects and hides facial features (through blurring or other means) of all photographs taken using the app. This would have the dual benefit of ensuring privacy while also broadening the subject matter available to the participants-thus allowing more natural and ecologically valid photographs to be used in the clinical or research setting.

The study illustrated the value of including a communication partner in the $\mathrm{AR}$ process. The communication partners reported learning a lot about their hearingimpaired partner's hearing and hearing aids, they felt it gave them the opportunity to share their perspective about communication, and that it gave them greater insight into their partner's hearing difficulties. These are some of the factors that underlie the value of familycentered audiological care (Hallberg and Barrenäs, 1994; Habanec and Kelly-Campbell, 2015; Singh et al, 2016). Audiologists rarely involve family members in audiological care, being present at less than $30 \%$ of appointments, and then only being involved in $12 \%$ of the total interaction time (Ekberg et al, 2015). Oftencited reasons for not implementing family-centered care in audiological practice are concerns about the complexities of family dynamics, uncertainty as to what to do when there is a mismatch between the needs and priorities of the client and the family member, and being unsure about how to involve family members in the conversation (Ekberg et al, 2014b; 2015; Meyer et al, 2015). Use of photovoice would seem to be a simple and effective way to involve both partners in conversation, in a safe environment in which mismatches in opinion can be discussed.

The personal nature of the debriefing sessions suggested that participants trusted the research team. High trust and good patient-provider communication are associated with greater satisfaction with health care, better adherence to treatment recommendations, and better self-management (Safran et al, 1998; Clark, 2003; Wanzer et al, 2004; Bendapudi et al, 2006). Based on the nature of photovoice, it is perhaps not surprising this is the case, but nonetheless it can be postulated that using photovoice as a clinical counseling tool would enhance satisfaction, adherence, and self-management.

The instruction to document both positive and negative hearing aid experiences is atypical of data collected in most clinical appointments and research protocols. Typically, individuals are only queried about residual problems and problematic circumstances. The data here illustrate the value of having individuals document both positive and negative hearing aid experiences, regardless of whether photovoice is used as a tool. This is well illustrated by the case described previously in which the participant began using her hearing aids more because she had become aware that the hearing aids were beneficial in situations that she had not previously thought about. Had she been instructed to only focus on problematic listening situations, it is quite likely that her hearing aid use would not have changed. We, therefore, encourage clinicians and researchers alike to document positive hearing aid outcome because it can motivate hearing aid use.

In general, the counseling advice focusing on communication strategies and rehabilitation devices was fairly standard. However, the fact that it could be highly tailored to the participant's experiences using their own photographs seemed to make the advice understandable to participants and, thus, likely easy to apply and retain. The differences in patient lifestyle, needs, and preferences were evident when looking at and discussing photographs. This kind of insight could be very useful for audiologists when selecting assistive technology, and while empirical evidence is needed, our observation suggests that obtaining the information from photographs was more efficient and targeted than obtaining the information from an interview. Furthermore, the individual differences in lifestyle demonstrate the need for patient- and family-centered interventions and counseling. Photovoice can be used 
to guide selection of rehabilitation recommendations, and for postfitting counseling.

Recall that our goal was to examine the feasibility of using an adapted version of photovoice as a clinical tool; we did not aim to identify thematic content in the interviews nor did we apply a formal qualitative analytical approach. Furthermore, because we are interested in the application of photovoice methodology in clinical audiology, we did not provide the research team with training in qualitative interviewing. This was an intentional decision that was made in order that clinical utility could be evaluated.

Being a feasibility study, there are limitations regarding the extent to which the findings can be applied to a clinical sample. First, participants consisted of a convenience sample of 24 individuals recruited from a database of prior volunteers who received payment for taking part; thus, they were possibly more motivated to adhere to the study protocol of taking photographs than a clinical sample might be. Second, formal outcome measures were not included in the study design. This was because our goal was to answer questions, such as "are people willing to use photovoice," "is it considered acceptable," and "how much time might it take if it is implemented as a clinical tool," rather than to assess its impact on AR outcomes. In the future, the impact of photovoice in clinical outcomes will be examined in a controlled, statistically powered research study using standardized outcome measures. Third, we only asked 12 participants what they would think if they were asked to bring photographs to a clinical appointment; thus, we have little data from which to draw conclusions about this issue. Clearly, patient acceptance of the method would be critical if it were to be used clinically. As with many clinical procedures, it is likely that a proportion of individuals would object to doing this. In such cases, as noted previously, using preselected photographs could in part address this.

In summary, this feasibility study suggests that an adapted form of photovoice methodology could be a highly promising tool for AR when used to facilitate provision of tailored communication strategy counseling, as a posthearing aid fitting counseling tool, to enhance communication between partners regarding hearing loss, and to provide insight into the emotional impacts of hearing loss. In the future, a statistically powered, controlled research study using standardized outcome measures and a broader clinical population will be conducted.

\section{REFERENCES}

Angelo J, Egan R. (2015) Family caregivers voice their needs: a photovoice study. Palliat Support Care 13(3):701-712.

Baker TA, Wang CC. (2006) Photovoice: use of a participatory action research method to explore the chronic pain experience in older adults. Qual Health Res 16(10):1405-1413.
Bendapudi NM, Berry LL, Frey KA, Parish JT, Rayburn WL. (2006) Patients' perspectives on ideal physician behaviors. Mayo Clin Proc 81(3):338-344.

Bowen DJ, Kreuter M, Spring B, Cofta-Woerpel L, Linnan L, Weiner D, Bakken S, Kaplan CP, Squiers L, Fabrizio C, Fernandez M. (2009) How we design feasibility studies. Am J Prev Med 36(5):452-457.

Clark PA. (2003) Medical practices' sensitivity to patients' needs: opportunities and practices for improvement. J Ambul Care Manage 26(2):110-123.

Clements K. (2012) Participatory action research and photovoice in a psychiatric nursing/clubhouse collaboration exploring recovery narrative. J Psychiatr Ment Health Nurs 19:785-791.

Davis K, Schoenbaum SC, Collins KS, Tenney K, Hughes DL, Audet AJ. (2002) Room for Improvement: Patients Report on the Quality of Their Health Care. New York, NY: Commonwealth Fund.

Ekberg K, Grenness C, Hickson L. (2014a) Addressing patients' psychosocial concerns regarding hearing aids within audiology appointments for older adults. Am J Audiol 23:337-350.

Ekberg K, Meyer C, Scarinci N, Barr K, Hickson L. (2014b) Disagreements between clients and family members regarding clients' hearing and rehabilitation within audiology appointments for older adults. J Interactional Res Commun Disord 5:217-244.

Ekberg K, Meyer C, Scarinci N, Grenness C, Hickson L. (2015) Family member involvement in audiology appointments with older people with hearing impairment. Int J Audiol 54(2):70-76.

Gill R, Black A, Dumont T, Fleming N. (2016) Photovoice: a strategy to better understand the reproductive and sexual health needs of young mothers. J Pediatr Adolesc Gynecol 29(5):467-475.

Ginicola MM, Smith C, Trzaska J. (2012) Counseling through images: using photography to guide the counseling process and achieve treatment goals. J Creat Ment Health 7:310-329.

Grenness C, Hickson L, Laplante-Lévesque A, Meyer C, Davidson B. (2015) Communication patterns in audiologic rehabilitation history-taking: audiologists, patients, and their companions. Ear Hear 36(2):191-204.

Grenness C, Meyer C, Scarinci N, Ekberg K, Hickson L. (2016) The international classification of functioning, disability and health as a framework for providing patient- and family-centered audiological care for older adults and their significant others. Semin Hear 37(3):187-199.

Guerra SR, Rodrigues SP, Demain S, Figueiredo DM, Sousa LX. (2013) Evaluating proFamilies-dementia: adopting photovoice to capture clinical significance. Dementia 12(5):569-587.

Habanec OL, Kelly-Campbell RJ. (2015) Outcomes of group audiological rehabilitation for unaided adults with hearing impairment and their significant others. Am J Audiol 24(1):40-52.

Hallberg LRM, Barrenäs ML. (1994) Group rehabilitation of middleaged males with noise-induced hearing loss and their spouses: evaluation of short-and long-term effects. Br J Audiol 28(2):71-79.

Houts PS, Doak CC, Doak LG, Loscalzo MJ. (2006) The role of pictures in improving health communication: a review of research on attention, comprehension, recall, and adherence. Patient Educ Couns 61(2):173-190.

Kowitt S, Woods-Jaeger B, Lomas J, Taggart T, Thayer L, Sutton S, Lightfoot AF. (2015) Using photovoice to understand barriers to and facilitators of cardiovascular health among African 
American adults and adolescents, North Carolina, 2011-2012. Prev Chronic Dis 12:E164.

Laplante-Lévesque A, Hickson L, Grenness C. (2014) An Australian survey of audiologists' preferences for patient-centredness. Int $J$ Audiol 53(1, Suppl):S76-S82.

Linz S, Hanrahan NP, DeCesaris M, Petros R, Solomon P. (2016) Clinical use of an autovideography intervention to support recovery in individuals with severe mental illness. J Psychosoc Nurs Ment Health Serv 54(5):33-40.

Lorenz LS, Chilingerian JA. (2011) Using visual and narrative methods to achieve fair process in clinical care. J Vis Exp 48:e2342.

Meyer C, Scarinci N, Ryan B, Hickson L. (2015) “This is a partnership between all of us": audiologists' perceptions of family member involvement in hearing rehabilitation. Am J Audiol 24(4): $536-548$.

Oliffe JL, Bottorff JL. (2007) Further than the eye can see? Photo elicitation and research with men. Qual Health Res 17(6):850-858.

Orsmond GI, Cohn ES. (2015) The distinctive features of a feasibility study: objectives and guiding questions. OTJR 35(3): 169-177.

Poost-Foroosh L, Jennings MB, Cheesman MF. (2015) Comparisons of client and clinician views of the importance of factors in client-clinician interaction in hearing aid purchase decisions. $J$ Am Acad Audiol 26(3):247-259.

Pryce H, Hall A, Laplante-Lévesque A, Clark E. (2016) A qualitative investigation of decision making during help-seeking for adult hearing loss. Int J Audiol 55(11):658-665.
Rosen D, Goodkind S, Smith ML. (2011) Using photovoice to identify service needs of older African American methadone clients. $J$ Soc Serv Res 37(5):526-538.

Sackett CR, Jenkins AM. (2015) Photovoice: fulfilling the call for advocacy in the counseling field. J Creat Ment Health 10:376-385.

Safran DG, Taira DA, Rogers WH, Kosinski M, Ware JE, Tarlov AR. (1998) Linking primary care performance to outcomes of care. J Fam Pract 47(3):213-220.

Sandelowski M. (2000) Whatever happened to qualitative description? Res Nurs Health 23(4):334-340.

Saunders GH, Frederick MT, Silverman SC, Nielsen C, LaplanteLévesque A. (2017) Development and pilot evaluation of a novel theory-based intervention to encourage help seeking for adult hearing loss. J Am Acad Audiol 28(10):920-931.

Sciacca A, Meyer C, Ekberg K, Barr C, Hickson L. (2017) Exploring audiologists' language and hearing aid uptake in initial rehabilitation appointments. Am J Audiol 26(2):110-118.

Singh G, Hickson L, English K, Scherpiet S, Lemke U, Timmer B, Buerkli-Halevy O, Montano J, Preminger J, Scarinci N, Saunders G, Jennings MB, Launer S. (2016) Family-centered adult audiologic care: a phonak position statement. Hear Rev 23(4):16.

True G, Rigg KK, Butler A. (2015) Understanding barriers to mental health care for recent war veterans through photovoice. Qual Health Res 25(10):1443-1455.

Wanzer MB, Booth-Butterfield M, Gruber K. (2004) Perceptions of health care providers' communication: relationships between patient-centered communication and satisfaction. Health Commun 16(3):363-384. 